\title{
A comparative study on heat dissipation, morphological and magnetic properties of hyperthermia suitable nanoparticles prepared by co-precipitation and hydrothermal methods
}

\author{
MD SHARIFUL ISLAM, YOSHIHUMI KUSUMOTO*, JUNICHI KURAWAKI, \\ MD ABDULLA-AL-MAMUN and HIROTAKA MANAKA ${ }^{\dagger}$ \\ Department of Chemistry and Bioscience, Graduate School of Science and Engineering, Kagoshima University, \\ 1-21-35 Korimoto, Kagoshima 890-0065, Japan \\ $\dagger$ Department of Electrical and Electronics Engineering, Graduate School of Science and Engineering, \\ Kagoshima University, 1-21-35 Korimoto, Kagoshima 890-0065, Japan
}

MS received 5 December 2011; revised 14 April 2012

\begin{abstract}
Magnetite $\left(\mathrm{Fe}_{3} \mathrm{O}_{4}\right)$ nanoparticles were prepared by co-precipitation and hydrothermal methods and their phase transfer was done successfully to compare their performances in different aspects. Synthesized nanoparticles were characterized for XRD, FE-SEM, TEM, UV-Vis absorption (reflectance) spectra, magnetic hysteresis loops and a.c. magnetic field induced hyperthermia. The magnetic nanoparticles prepared by the co-precipitation method show superior performances in respect of heat dissipation capability, saturation of magnetization values and particle size when compared to those prepared by the hydrothermal method.
\end{abstract}

Keywords. Heat dissipation; hyperthermia; hysteresis loops; reproducibility; magnetic nanoparticles.

\section{Introduction}

The synthesis of nanostructured magnetic materials has become a particularly important area of research and is attracting a growing interest because of the potential applications such materials have in ferrofluids, advanced magnetic materials, catalysts, coloured pigments, high-density magnetic recording media and medical diagnostics (Caruso et al 2001; Hyeon et al 2001; Yu et al 2002; Xiong et al 2003; Woo et al 2003; Wang et al 2003). Magnetic iron oxide nanoparticles and their dispersions in various media have long been of scientific and technological interest. Iron oxides exist in many forms in nature, with magnetite $\left(\mathrm{Fe}_{3} \mathrm{O}_{4}\right)$, maghemite $\left(\gamma-\mathrm{Fe}_{2} \mathrm{O}_{3}\right)$ and hematite $\left(\alpha-\mathrm{Fe}_{2} \mathrm{O}_{3}\right)$ which are probably most common (Cornell and Schwertmann 2003). Magnetite $\left(\mathrm{Fe}_{3} \mathrm{O}_{4}\right)$ has recently been considered an ideal candidate for biological applications, both as a tag for sensing and imaging, and as an activity agent for antitumor therapy (Häfeli et al 1997; Louie et al 2000; Perez et al 2004). Magnetite and maghemite have attracted attention in biomedical applications because of their biocompatibility and low toxicity in the human body (Tartaj et al 2005; Kim et al 2006). Magnetite and hematite have been used as catalysts for a number of industrially important reactions (Bautista et al 2007; Shi et al 2007; Li et al 2008), including the synthesis of $\mathrm{NH}_{3}$ (the Haber process), the high

\footnotetext{
*Author for correspondence (kusumoto@ sci.kagoshima-u.ac.jp)
}

temperature water gas shift reaction and the desulfurization of natural gas. The therapeutic potential of nanoparticles with a controlled and adapted size has been demonstrated in cases, where hyperthermia has been recognized as a promising therapy to treat tumorous areas (Bertorelle et al 2003; Perrin-Cocon et al 2003).

Superparamagnetic nanoparticles when exposed to an alternating magnetic field can be used to heat tumor cells to $41-45^{\circ} \mathrm{C}$, where tissue damage for normal tissue is reversible while the tumor cells are irreversibly damaged (Neuberger et al 2005). Under hydrothermal conditions, a broad range of nanostructured materials can be formed; this strategy is based on a general phase transfer and separation mechanism occurring at the interfaces of the liquid, solid and solution phases present during synthesis. In the co-precipitation method, size, shape and composition of the magnetic nanoparticles strongly depend on the type of salts used (e.g. chlorides, sulfates, nitrates), the $\mathrm{Fe}^{2+} / \mathrm{Fe}^{3+}$ ratio, the reaction temperature, the $\mathrm{pH}$ value and ionic strength of the media ( $\mathrm{Lu}$ et al 2007). While a number of suitable methods have been developed for the synthesis of magnetic nanoparticles (MNPs) of various different compositions, successful application of such magnetic nanoparticles in the areas listed above is highly dependent on the stability of the particles under a range of different conditions. Although hydrothermal and co-precipitation methods are based on the wet chemical synthesis, there are some significant differences in synthesized MNPs followed by both methods and they are also discussed for comparison in our study to find out their hyperthermia potentiality. 


\section{Experimental}

\subsection{Materials and methods}

Typical syntheses of magnetic nanoparticles (MNPs) were carried out in a hydrothermal system by modified reduction reactions between $\mathrm{FeCl}_{2}$ and ethylene glycol and the reaction between $\mathrm{Fe}^{2+}$ and $\mathrm{Fe}^{3+}$ in a co-precipitation method (Hong et al 2005; Anselm 2008). In this experiment, chemicals used for synthesis of MNPs by both methods were iron chloride hexahydrate $\left(\mathrm{FeCl}_{3} \cdot 6 \mathrm{H}_{2} \mathrm{O}\right)$, ethylene glycol $(99 \cdot 5 \%)$, $\mathrm{FeCl}_{3}, \mathrm{HCl}, 25 \% \mathrm{NH}_{3}$ solution (Wako Pure Chemical Industries Ltd., Japan), $\mathrm{FeCl}_{2}$ (Strem Chemicals, Newburyport), polyethylene glycol 4000 (Tokyo Kasei Kogyo Co. Ltd, Japan) and anhydrous sodium acetate (NaAc, 98\%, Nacalai Tesque, Japan). All chemicals were of analytical grade and used without any further purification.

\subsection{Hydrothermal synthesis of magnetic nanoparticles (MNPs)}

$\mathrm{FeCl}_{3} \cdot 6 \mathrm{H}_{2} \mathrm{O}(1.352 \mathrm{~g}, 5 \mathrm{mmol})$ was dissolved in ethylene glycol $(40 \mathrm{~mL})$ to form a clear solution, followed by the addition of NaAc $(3.6 \mathrm{~g})$ and polyethylene glycol $(1.0 \mathrm{~g})$. The mixture was stirred vigorously for $45 \mathrm{~min}$ until getting a clear solution and then sealed in a teflonlined stainlesssteel autoclave $(50 \mathrm{~mL}$ capacity). The autoclave was heated to and maintained at $200{ }^{\circ} \mathrm{C}$ for $5 \mathrm{~h}$ and allowed to cool to room temperature. After cooling, decantation was done by a permanent magnet to get the sedimented black products. The black products were washed several times with ethanol and dried at $70{ }^{\circ} \mathrm{C}$ for $3 \mathrm{~h}$. Finally, we obtained $\mathrm{Fe}_{3} \mathrm{O}_{4}$ nanoparticles.

\subsection{Synthesis of MNPs by co-precipitation method}

In a typical co-precipitation method, $\mathrm{FeCl}_{3}(2 \cdot 6 \mathrm{~g})$ and $\mathrm{FeCl}_{2}$ $(1.3 \mathrm{~g})$ were dissolved in nitrogen gas $\left(\mathrm{N}_{2}\right)$ purged $2.0 \mathrm{M}$ hydrochloric acid solution and magnetically stirred under a continuous flow of $\mathrm{N}_{2}$. The mixture was heated at $70{ }^{\circ} \mathrm{C}$ for $30 \mathrm{~min}$ and then the mixture was again heated for another 5 min under a blanket of $\mathrm{N}_{2}$. Ammonia was added drop by drop to precipitate the magnetic nanoparticles and the black product formed was treated hydrothermally at $70{ }^{\circ} \mathrm{C}$ for $30 \mathrm{~min}$. All aqueous solutions and suspensions were made using nanopure water $(18 \mathrm{M} \Omega \mathrm{cm}$ resistances). The resulting nanoparticles were subsequently separated from the reaction media under magnetic field and washed three times with nanopure water before drying. Finally the MNPs were oven dried at $70{ }^{\circ} \mathrm{C}$ for $3 \mathrm{~h}$ to get $\mathrm{Fe}_{3} \mathrm{O}_{4}$.

\subsection{Phase transfer of $\mathrm{Fe}_{3} \mathrm{O}_{4}$ to $\gamma-\mathrm{Fe}_{2} \mathrm{O}_{3}$ and $\alpha-\mathrm{Fe}_{2} \mathrm{O}_{3}$}

It is well known that $\mathrm{Fe}_{3} \mathrm{O}_{4}$ can be oxidized to $\gamma-\mathrm{Fe}_{2} \mathrm{O}_{3}$, which can be further transformed into $\alpha-\mathrm{Fe}_{2} \mathrm{O}_{3}$ at higher temperature (Bate 1975). However, magnetite $\left(\mathrm{Fe}_{3} \mathrm{O}_{4}\right)$ is not
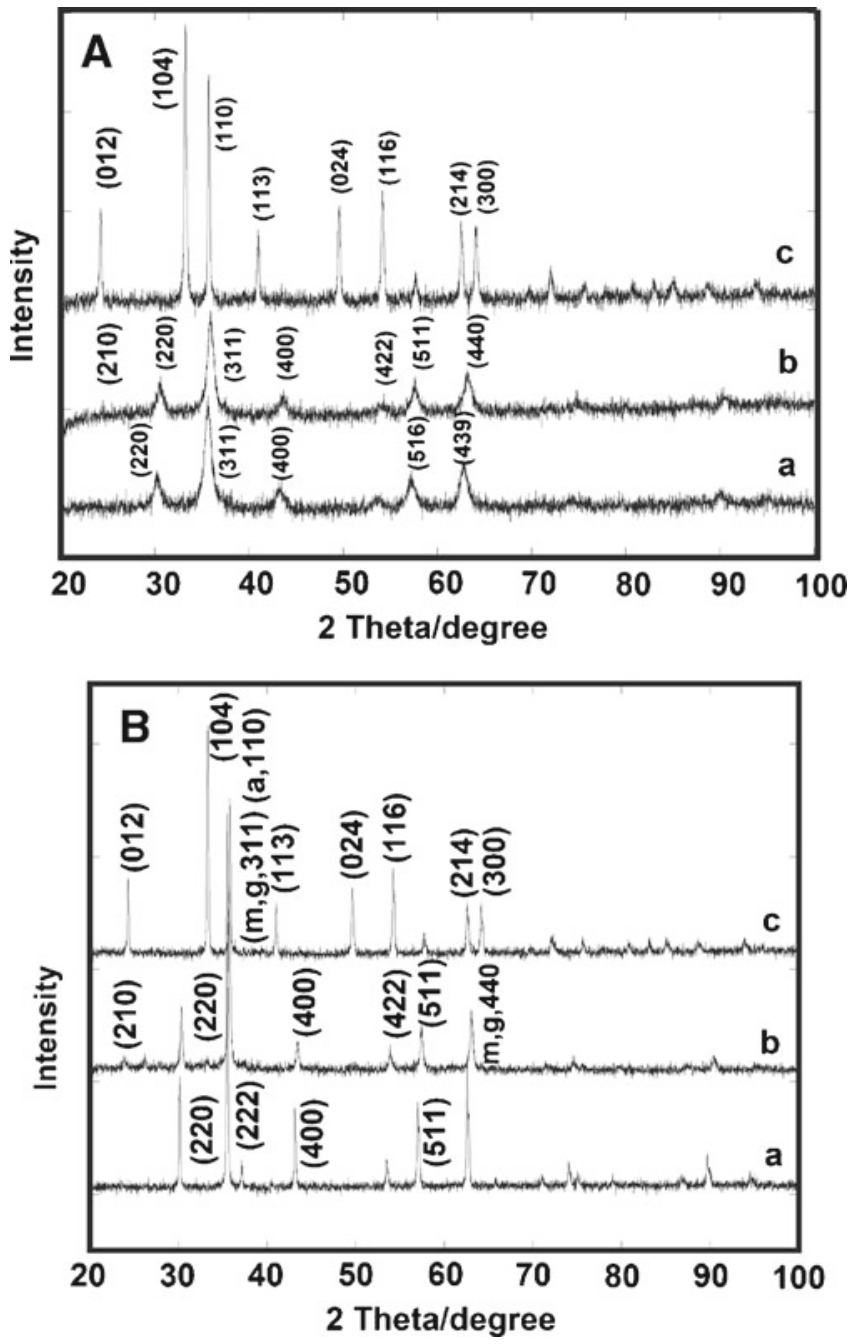

Figure 1. XRD patterns of MNPs synthesized by (A) coprecipitation and (B) hydrothermal methods. Magnetite, maghemite and hematite are represented by (a), (b) and (c), respectively in both plates (A) and (B).

very stable and is sensitive to oxidation. Magnetite is transformed into maghemite $\left(\gamma-\mathrm{Fe}_{2} \mathrm{O}_{3}\right)$ in the presence of oxygen (Laurent et al 2008). In figures $1 \mathrm{~A}$ and $\mathrm{B}$, (a) is the XRD pattern of the as-synthesized black $\mathrm{Fe}_{3} \mathrm{O}_{4}$ nanoparticles assembly by both methods. After oxidation at $250^{\circ} \mathrm{C}$ for $6 \mathrm{~h}$, the black assembly is transformed into a red-brown one. Image (b) for both plates of figure 1 shows all XRD peak positions and relative intensities of this red-brown material, whereas image (c) shows XRD of the dark red-brown materials, $\alpha-\mathrm{Fe}_{2} \mathrm{O}_{3}$, obtained after $500{ }^{\circ} \mathrm{C}$ annealing of $\gamma-\mathrm{Fe}_{2} \mathrm{O}_{3}$ in figure $1 \mathrm{~A}(\mathrm{~b})$ and $\mathrm{B}(\mathrm{b})$ under $\mathrm{Ar}$ gas for $1 \mathrm{~h}$. However, the as-synthesized $\mathrm{Fe}_{3} \mathrm{O}_{4}$ nanoparticles do not go through such a change if annealed under inert atmosphere. Even at $650{ }^{\circ} \mathrm{C}$, $\mathrm{Fe}_{3} \mathrm{O}_{4}$ structure is still retained, as evidenced by both XRD and TEM (data not shown). This confirms that the valence state of the iron cations in the as-synthesized sample closely matches with that of $\mathrm{Fe}_{3} \mathrm{O}_{4}$ rather than similarly structured $\gamma-\mathrm{Fe}_{2} \mathrm{O}_{3}$ (Sun et al 2004). 


\section{Structure and magnetic characterization}

The structural characterization including size and crystal structure of the as-synthesized magnetic nanoparticles by both methods was performed for all the samples without any size sorting. To further confirm the crystal structure and overall phase purity, nanoparticles with different sizes were examined using a PANalytical Advance X-ray diffractometer (XRD) with $\mathrm{CuK} \alpha$ radiation and a Ni filter. The surface morphology and nanoparticles size were determined using a field emission scanning electron microscope (FE-SEM, Hitachi $\mathrm{S}-4100 \mathrm{H})$. Absorption spectra were recorded on UV-Vis absorption (reflectance) spectrophotometer (Shimadzu Corporation, UV-2450, Japan). The samples were standardized with barium sulphate coated glass substrate and its spectrum was used as the baseline. The spectra of all samples were measured in a wavelength range between 240 and 850 $\mathrm{nm}$. AC magnetic field induced heating capability of magnetic nanoparticles was examined to observe the hyperthermia potentiality of $\mathrm{Fe}_{3} \mathrm{O}_{4}$ and $\gamma-\mathrm{Fe}_{2} \mathrm{O}_{3}$ (for both methods) by dispersing the nanoparticles in distilled water as well as a minimum essential medium (MEM) and magnetic hysteresis loops were measured by a superconducting quantum interference device (SQUID, Quantum Design MPMS-5). Further, shapes of the nanoparticles were analysed by transmission electron microscopy (TEM) using a JEOL JEM-3010 VII TEM operating at $300 \mathrm{kV}$.

\section{Reproducibility of magnetic $\left(\mathrm{Fe}_{3} \mathrm{O}_{4}, \gamma-\mathrm{Fe}_{2} \mathrm{O}_{3}\right.$ and $\alpha-\mathrm{Fe}_{2} \mathrm{O}_{3}$ ) nanoparticles}

An important aspect of the synthesis of magnetic nanomaterials is the reproducibility when they are synthesized using identical conditions. To test the reproducibility of magnetic nanoparticles, three samples were synthesized under optimum conditions already described in $\S \S 2.2,2.3$ and 2.4. All the characterizations of these samples were performed in accordance with $\S 3$ and these three samples were found to have fairly consistent values for maximum reproducing capability. These results show excellent reproducibility for the synthesized magnetic nanoparticles by simple hydrothermal and co-precipitation methods which may be the key point for commercial production.

\section{Results and discussion}

The crystal structures of the prepared MNPs were observed by XRD measurement. Typical XRD patterns of $\mathrm{Fe}_{3} \mathrm{O}_{4}$, $\gamma-\mathrm{Fe}_{2} \mathrm{O}_{3}$ and $\alpha-\mathrm{Fe}_{2} \mathrm{O}_{3}$ are shown in figure 1. As shown in figure 1 , all samples were found to be consistent with the expected diffraction pattern of the $f c c \mathrm{FeO}$ structures for both methods. No diffraction peaks from other crystalline forms are detected, demonstrating that these $\mathrm{Fe}_{3} \mathrm{O}_{4}, \gamma-\mathrm{Fe}_{2} \mathrm{O}_{3}$ and $\alpha-\mathrm{Fe}_{2} \mathrm{O}_{3}$ samples have high purity and crystallinity. Figure $1 \mathrm{~A}$ demonstrated the peak indexes of (a) $\mathrm{Fe}_{3} \mathrm{O}_{4}$, (b) $\gamma-\mathrm{Fe}_{2} \mathrm{O}_{3}$ and (c) $\alpha-\mathrm{Fe}_{2} \mathrm{O}_{3}$ synthesized by co-precipitation method whereas the peak indexes of (a) $\mathrm{Fe}_{3} \mathrm{O}_{4}$, (b) $\gamma$ $\mathrm{Fe}_{2} \mathrm{O}_{3}$ and (c) $\alpha-\mathrm{Fe}_{2} \mathrm{O}_{3}$ synthesized by hydrothermal method is shown in figure 1B. More sharp narrower peaks were noticed among all the iron oxides prepared by hydrothermal method due to the larger particle size of $\sim 45-50 \mathrm{~nm}$. In contrast, wide and broader peaks were noticed among all the iron oxides prepared by co-precipitation method due to the smaller particle size of $\sim 15-20 \mathrm{~nm}$.

Particles morphology of all the samples was studied using FE-SEM (figure 2). Figures $2 \mathrm{~A}$ and $\mathrm{B}$ represent FE-SEM
A

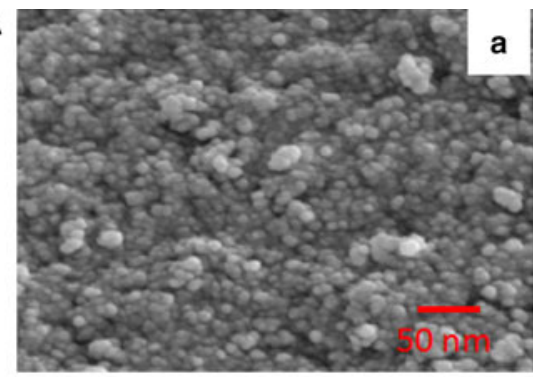

B

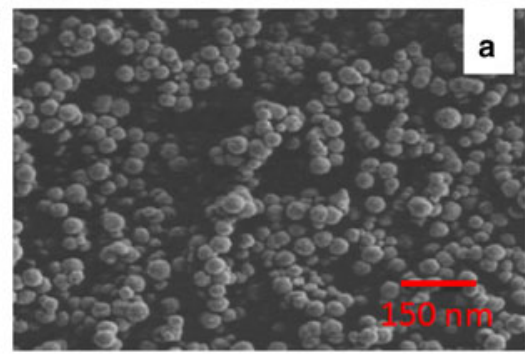

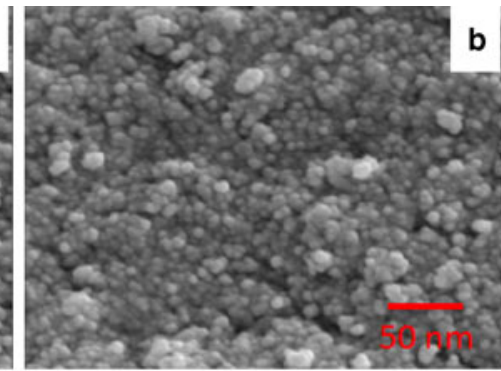
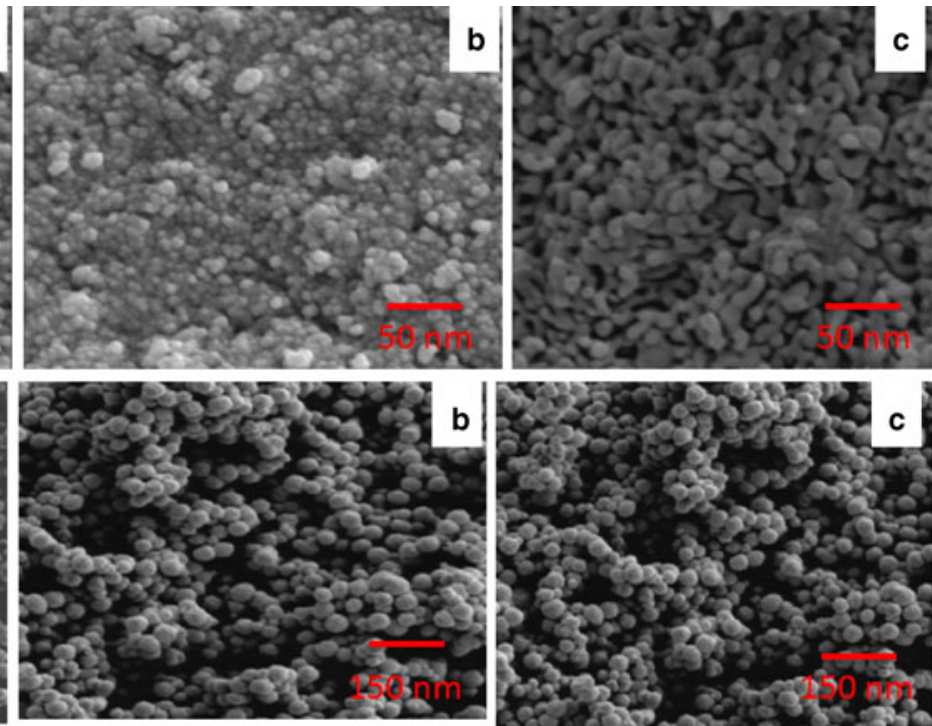

Figure 2. Comparative SEM images of magnetite, maghemite and hematite nanoparticles represented by (a), (b) and (c), respectively. Plate (A) for co-precipitation and (B) for hydrothermal method. 
Table 1. Comparative performance of MNPs prepared by co-precipitation and hydrothermal methods.

\begin{tabular}{|c|c|c|c|c|c|c|}
\hline \multirow[b]{2}{*}{ Property } & \multicolumn{3}{|c|}{ Co-precipitation } & \multicolumn{3}{|c|}{ Hydrothermal } \\
\hline & $\begin{array}{c}\text { Magnetite } \\
\mathrm{Fe}_{3} \mathrm{O}_{4}\end{array}$ & $\begin{array}{l}\text { Maghemite } \\
\gamma-\mathrm{Fe}_{2} \mathrm{O}_{3}\end{array}$ & $\begin{array}{l}\text { Hematite } \\
\alpha-\mathrm{Fe}_{2} \mathrm{O}_{3}\end{array}$ & $\begin{array}{c}\text { Magnetite } \\
\mathrm{Fe}_{3} \mathrm{O}_{4}\end{array}$ & $\begin{array}{c}\text { Maghemite } \\
\gamma-\mathrm{Fe}_{2} \mathrm{O}_{3}\end{array}$ & $\begin{array}{l}\text { Hematite } \\
\alpha-\mathrm{Fe}_{2} \mathrm{O}_{3}\end{array}$ \\
\hline Particle size (SEM) & $15-20 \mathrm{~nm}$ & $15-20 \mathrm{~nm}$ & $20-25 \mathrm{~nm}$ & $45-50 \mathrm{~nm}$ & $45-55 \mathrm{~nm}$ & $50-60 \mathrm{~nm}$ \\
\hline Particle size (TEM) & $12-18 \mathrm{~nm}$ & $14-20 \mathrm{~nm}$ & $25-35 \mathrm{~nm}$ & $35-50 \mathrm{~nm}$ & $40-55 \mathrm{~nm}$ & $50-70 \mathrm{~nm}$ \\
\hline Particle shape & Spherical & Spherical & Neck structured & Spherical & Spherical & Spherical \\
\hline Absorption edge & $620 \mathrm{~nm}$ & $600 \mathrm{~nm}$ & $565 \mathrm{~nm}$ & $650 \mathrm{~nm}$ & $630 \mathrm{~nm}$ & $570 \mathrm{~nm}$ \\
\hline $\begin{array}{l}\text { Saturation value of } \\
\text { magnetization }\left(M_{\mathrm{S}}\right)\end{array}$ & $78 \mathrm{emu} / \mathrm{g}$ & $59 \mathrm{emu} / \mathrm{g}$ & $1.8 \mathrm{emu} / \mathrm{g}$ & $65 \mathrm{emu} / \mathrm{g}$ & $57 \mathrm{emu} / \mathrm{g}$ & $1.2 \mathrm{emu} / \mathrm{g}$ \\
\hline
\end{tabular}
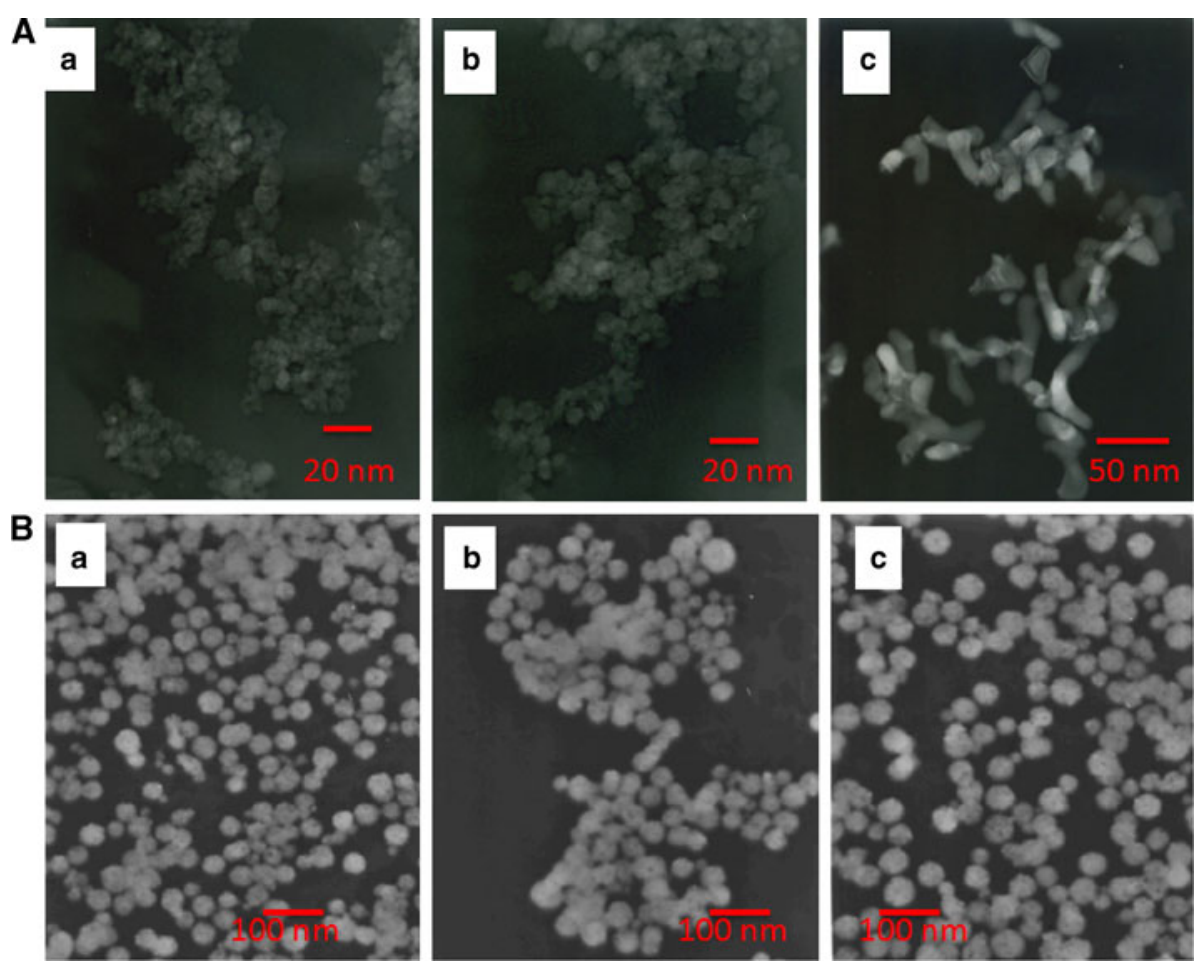

Figure 3. Comparative TEM images of magnetite, maghemite and hematite nanoparticles represented by (a), (b) and (c), respectively. Plate (A) for co-precipitation and (B) for hydrothermal method.

micrographs of (a) $\mathrm{Fe}_{3} \mathrm{O}_{4}$, (b) $\gamma-\mathrm{Fe}_{2} \mathrm{O}_{3}$ and (c) $\alpha-\mathrm{Fe}_{2} \mathrm{O}_{3}$ synthesized by co-precipitation and hydrothermal methods, respectively. The nanoparticles size was roughly estimated to be about $15-20 \mathrm{~nm}$ and $45-55 \mathrm{~nm}$ prepared by co-precipitation and hydrothermal methods, respectively. This result revealed that co-precipitation method facilitates smaller size nanoparticles than hydrothermal method (table 1).

The samples were also characterized using TEM (figure 3) to analyse shape and size of the particles. Here figures $3 \mathrm{~A}$ and $\mathrm{B}$ depict TEM micrographs of (a) $\mathrm{Fe}_{3} \mathrm{O}_{4}$, (b) $\gamma-\mathrm{Fe}_{2} \mathrm{O}_{3}$ and (c) $\alpha-\mathrm{Fe}_{2} \mathrm{O}_{3}$ synthesized by co-precipitation and hydrothermal methods, respectively. Spherical-shaped morphology was observed by $\mathrm{FE}-\mathrm{SEM}$ in (a) $\mathrm{Fe}_{3} \mathrm{O}_{4}$ and (b) $\gamma-\mathrm{Fe}_{2} \mathrm{O}_{3}$ but neck-structured in (c) $\alpha-\mathrm{Fe}_{2} \mathrm{O}_{3}$ (figure $2 \mathrm{~A}$ ) for co-precipitation method whereas all spherical-shaped morphology was found in (a) $\mathrm{Fe}_{3} \mathrm{O}_{4}$, (b) $\gamma-\mathrm{Fe}_{2} \mathrm{O}_{3}$ and (c) $\alpha-\mathrm{Fe}_{2} \mathrm{O}_{3}$ synthesized by hydrothermal method (figure $2 \mathrm{~B}$ ). TEM images also clearly support FE-SEM data in terms of morphological and nanostructural analysis with particle size $\sim 12-25 \mathrm{~nm}$ and 35-55 $\mathrm{nm}$ synthesized by co-precipitation and hydrothermal method, respectively (table 1).

Figure 4 gives UV-Vis absorption (reflectance) spectra of the synthesized magnetic nanoparticles by both methods. As shown in figure 4, absorption spectra of (a) $\mathrm{Fe}_{3} \mathrm{O}_{4}$, (b) $\gamma$ $\mathrm{Fe}_{2} \mathrm{O}_{3}$ and (c) $\alpha-\mathrm{Fe}_{2} \mathrm{O}_{3}$ represents co-precipitation method whereas (d) $\mathrm{Fe}_{3} \mathrm{O}_{4}$, (e) $\gamma-\mathrm{Fe}_{2} \mathrm{O}_{3}$ and (f) $\alpha-\mathrm{Fe}_{2} \mathrm{O}_{3}$ represent the absorption spectra of MNPs synthesized by hydrothermal method. It can be seen that the absorption edges of coprecipitation synthesized MNPs are more red-shifted than 
those of MNPs synthesized by the hydrothermal method (table 1).

With the increase of calcination temperature $\left(500{ }^{\circ} \mathrm{C}\right)$, absorption edge of the sample has some blue shift. The blue shift is presumably ascribed to the formation of the homogenous $\mathrm{Fe}_{2} \mathrm{O}_{3}$ nanoparticles for both methods. The bandgap energy of $\mathrm{Fe}_{2} \mathrm{O}_{3}$ is $2.2 \mathrm{eV}$ and can be activated by the light below $563 \mathrm{~nm}$ (Karunakaran and Senthilvelan 2006).

To further explore the low temperature magnetic properties of $\mathrm{Fe}_{3} \mathrm{O}_{4}$ samples from both methods, $M-T$ curves in zero field cooling (ZFC) and field cooling (FC) processes with a $1 \mathrm{kOe}$ applied field were measured, as shown in figure 5. For the co-precipitation sample, ZFC magnetization $\left(M_{\mathrm{S}}\right)$ value was $9.8 \mathrm{emu} / \mathrm{g}(\mathrm{a})$ whereas for the hydrothermal $\mathrm{Fe}_{3} \mathrm{O}_{4}$ sample, the $\mathrm{ZFC}$ magnetization $\left(M_{\mathrm{s}}\right)$ value was

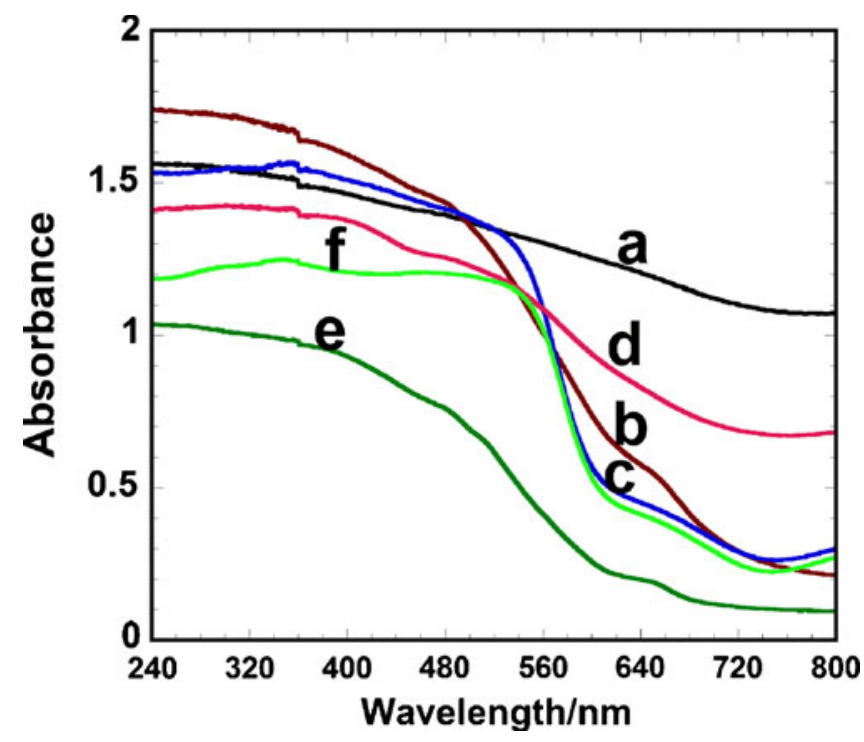

Figure 4. UV-Vis absorption (reflectance) spectra of MNPs. Magnetite, maghemite and hematite are represented by (a), (b), (c) and (d), (e), (f) for the co-precipitation and hydrothermal methods, respectively.
$7.8 \mathrm{emu} / \mathrm{g}$ (b), but no peak was observed for both samples by both methods.

The comparative hysteresis curves obtained at room temperature (figure 6) show that the saturation value of magnetization $\left(M_{\mathrm{s}}\right)$ of MNPs was prepared by both methods. Figures $6(\mathrm{~A})$ and (B) represent $M_{\mathrm{s}}$ value of (a) $\mathrm{Fe}_{3} \mathrm{O}_{4} 78$, $59 \mathrm{emu} / \mathrm{g}$ and (b) $\gamma-\mathrm{Fe}_{2} \mathrm{O}_{3} 65,57 \mathrm{emu} / \mathrm{g}$, respectively prepared by co-precipitation and hydrothermal methods. Moreover, figure $6(\mathrm{C})$ shows $M_{\mathrm{s}}$ value of $\alpha-\mathrm{Fe}_{2} \mathrm{O}_{3}$ nanoparticles prepared by (a) co-precipitation and (b) hydrothermal methods ( 1.8 and $1.2 \mathrm{emu} / \mathrm{g}$, respectively). Thus the results revealed that $M_{\mathrm{s}}$ values of all samples prepared by coprecipitation method were always higher than that of MNPs prepared by the hydrothermal method (table 1).

The $M_{\mathrm{s}}$ values for substances treated with oxygen and annealed are different from the mother sample for both cases. The difference in magnetization of both oxidized and nonoxidized samples indicates that the oxidation of magnetite into maghemite was completed and that maghemite was reduced at high temperature to hematite during annealing which was also supported by an XDR analysis.

Heat dissipation of magnetite and maghemite nanoparticles prepared by both methods was evaluated by using an a.c. magnetic field generator using maximum magnetic field intensity and a frequency of $5.0 \mathrm{kA} / \mathrm{m}$ and $560 \mathrm{~Hz}$, respectively. The heat generated from samples was evaluated by exposing $5 \mathrm{mg} / \mathrm{mL}$ magnetic particle suspension dispersed in distilled water and then their different doses like $0 \cdot 2$, $0.4,0.6,0.8$ and $1.0 \mathrm{~mL} / 5 \mathrm{~mL}$ MEM under an a.c. magnetic field for about $10 \mathrm{~min}$ exposure time. The comparative temperature rise of the as-prepared magnetic nanoparticles suspensions against the exposure time is shown in figure 7. The highest temperatures achieved by $\mathrm{Fe}_{3} \mathrm{O}_{4}$ and $\gamma-\mathrm{Fe}_{2} \mathrm{O}_{3}$ nanoparticles were $49.9,50.2^{\circ} \mathrm{C}$ and 49.2 and $49.7{ }^{\circ} \mathrm{C}$ prepared by co-precipitation and hydrothermal methods, respectively. Thus the findings revealed that the highest temperature was achieved by all the samples prepared by co-precipitation method, whereas temperature of the hydrothermally prepared sample increased gradually against time and heat dissipated was well below that of co-precipitation samples
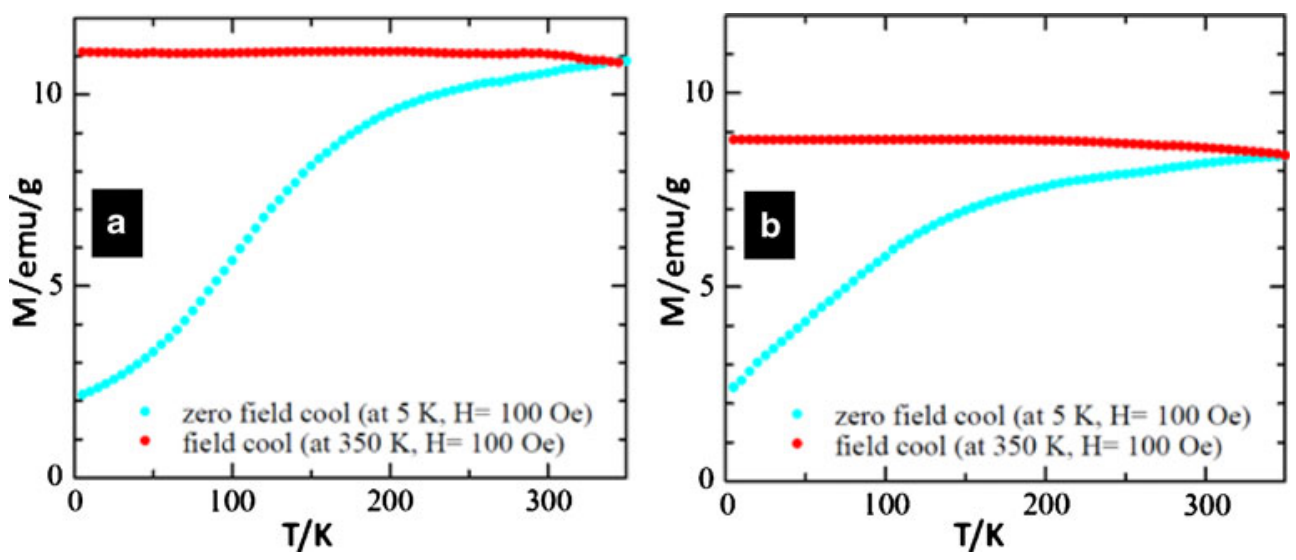

Figure 5. Temperature dependent magnetization in $\mathrm{ZFC}$ and $\mathrm{FC}$ processes for $\mathrm{Fe}_{3} \mathrm{O}_{4}$ synthesized by co-precipitation (a) and hydrothermal (b) methods. 

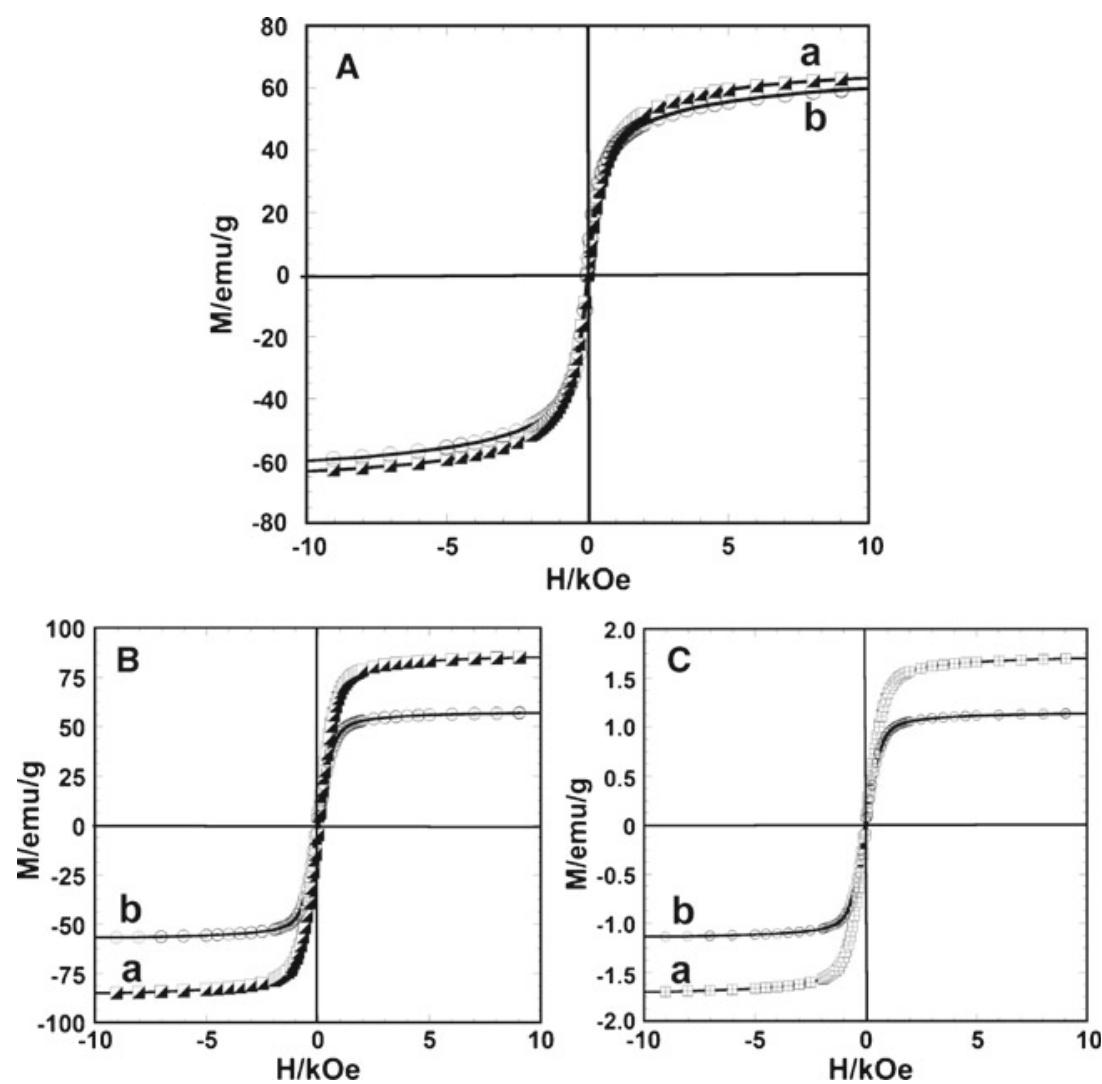

Figure 6. Comparative magnetic hysteresis loops of magnetic nanoparticles by coprecipitation and hydrothermal methods. Here $M_{\mathrm{s}}$ values of (a) $\mathrm{Fe}_{3} \mathrm{O}_{4}$ and (b) $\gamma$ $\mathrm{Fe}_{2} \mathrm{O}_{3}$ prepared by co-precipitation and hydrothermal methods are shown by (A) and (B), respectively whereas, $M_{\mathrm{S}}$ value of (C) $\alpha-\mathrm{Fe}_{2} \mathrm{O}_{3}$ nanoparticles is prepared by (a) co-precipitation and (b) hydrothermal methods.

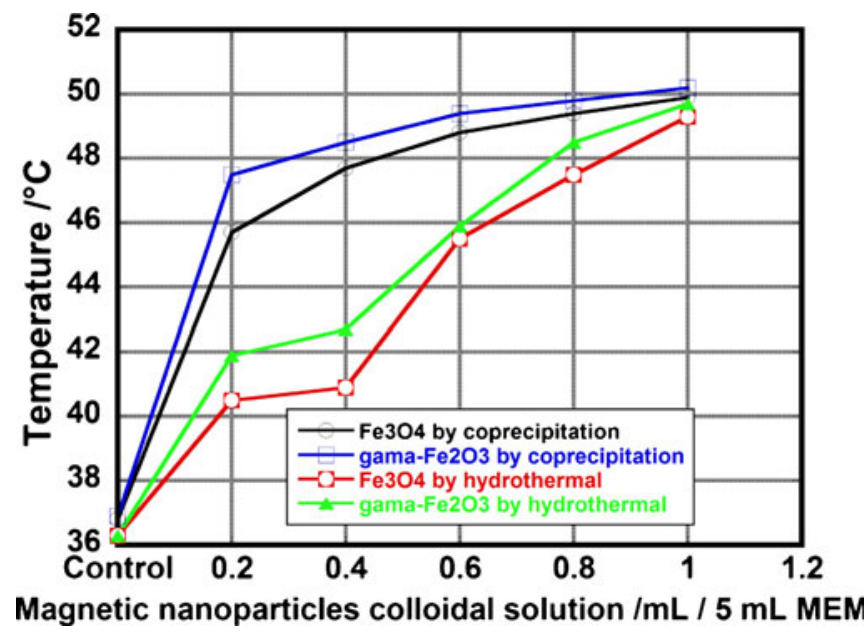

Figure 7. Comparative heat dissipation capability of MNPs by co-precipitation and hydrothermal methods.

(figure 7). Atsumia et al (2007) and Jeyadevan et al (2009) also reported that superparamagnetic nanoparticles prepared by the co-precipitation method dissipated highest heat to an a.c. magnetic field for hyperthermia. Finally, it is clear to conclude that the prepared nanomaterials have hyperthermia potentiality synthesized by both methods and hopefully, we are very much interested to use those materials in cancer therapy in future.

\section{Conclusions}

Comparative performances of MNPs prepared by both methods indicate that in respect of heat dissipation capability, saturation values of magnetization and particle size, coprecipitation method is better, whereas in respect of particle shape and absorbance (reflectance), the hydrothermal method is better. Precisely, we can draw a conclusion that MNPs synthesized by the co-precipitation method is better suited for hyperthermia than that by the hydrothermal method. But studies on a.c. magnetic field induced hyperthermia for carcinoma cells are our next step.

\section{Acknowledgements}

The present work was partly supported by Grant-in-Aid for Scientific Research (B) (No.19360367) and Challenging 
Exploratory Research (No. 23655204) from Japan Society for the Promotion of Science (JSPS) and Grant-in-Aid for JSPS Fellows (No. 2200083).

\section{References}

Anselm O 2008 Synthesis and characterization of tannic acid functionalized magnetic nanoparticles, in ACS symposium series 996 , (eds) R Nagarajan and T A Hatton (Washington DC: American Chemical Society) pp 90-107

Atsumia T, Jeyadevan B, Satob Y and Tohji K 2007 J. Magn. Magn. Mater. 3102841

Bate G 1975 in Magnetic oxides part 2 (ed.) D J Craik (New York: John Wiley \& Sons) pp 705-707

Bautista F M, Campelo J M, Luna D, Marinas J M, Quiros R A and Romero A A 2007 Appl. Catal. B70 611

Bertorelle F, Wilhelm C, Roger J, Gazeau F, Ménager C and Cabuil V 2003 Langmuir 225385

Caruso F, Spasova M, Susha A, Giersig M and Caruso R A 2001 Chem. Mater. 13109

Cornell R M and Schwertmann U 2003 The iron oxides: structure, properties, reactions, occurrences and uses (Weinheim: Wiley$\mathrm{VCH})$ 2nd ed.

Häfeli U, Schütt W, Teller J and Zborowski M 1997 Scientific and clinical application of magnetic carriers (New York: Plenum)

Hong D, Xiaolin L, Qing P, Xun W, Jinping C and Yadong L 2005 Angew. Chem. 1172842

Hyeon T, Lee S S, Park J, Chung Y and Na H B $2001 \mathrm{~J}$. Am. Chem. Soc. 12312798
Jeyadevan B, Atsumia T, Suto M, Kasuya R, Satob Y and Tohji K 2009 Thermal. Med. 254

Karunakaran C and Senthilvelan S 2006 Electrochem. Commun. 895

Kim J S, Yoon T J, Kim B G, Park J S, Kim H W, Lee K H, Park S B, Lee J K and Cho M H 2006 Toxicol. Sci. 89338

Laurent S, Forge D, Port M, Roch A, Robic C, Elst L V and Muller R N 2008 Chem. Rev. 1082064

Li C, Shen Y, Jia M, Sheng S, Adebajo M O and Zhu H 2008 Catal. Commun. 9355

Louie A Y, Huber M M, Ahrens E T, Rothbacher U, Moats R, Jacobs R E, Fraser S E and Meade T J 2000 Nat. Biotechnol. 18321

Lu An-Hui, Salabas E L and Schüth F 2007 Angew. Chem. Int. Ed. 461222

Neuberger T, Schopf B, Hofmann H, Hofmann M and Rechenberg B V 2005 J. Magn. Magn. Mater. 293483

Perez J M, Simeone F J, Tsourkas A, Josephson L and Weissleder R 2004 NanoLetters 4119

Perrin-Cocon L A, Marche P N and Villiers C L 2003 Biochem. J. 338123

Shi F, Tse M K, Pohl M M, Bruckner A, Zhang S M and Beller M 2007 Angew. Chem. Int. Ed. 468866

Sun S, Zeng H, Robinson D B, Raoux S, Rice P M, Wang S X and Li G 2004 J. Am. Chem. Soc. 126273

Tartaj P, Morales M P, Gonzalez-Carreno T, Veintemillas-Verdaguer S and Serna C J 2005 J. Magn. Magn. Mater. 29028

Wang Y, Wong J F, Teng X, Lin X Z and Yang H 2003 Nano. Lett. 31555

Woo K, Lee H J, Ahn J P and Park Y S 2003 Adv. Mater. 151761

Xiong Y, Xie Y, Chen S and Li Z 2003 Chem. Eur. J. 94991

Yu A C C, Mizuno M, Sasaki Y, Kondo H and Hiraga H 2002 Appl. Phys. Lett. 813768 